interests which he was earlier inclined to chide might have been one necessary condition of this tolerance (page 110).

Lecture 7 examines "the role of World 3 in producing the next generation"; making much, but never too much, of the crucial fact that it is thanks to this that "The creation of a cultured person" can now "be accomplished in a few years", whereas "it took at least 50,000 years to create a high civilisation" (page 123). This chapter contains one section which will especially delight any philosopher who has ever faulted Hume's Treatise of Human Nature for its "paralytic's eye view of causation": Eccles tells of experiments with kittens in gondolas which show that exploratory learning will not take place without active movements by the learner (page 132).

Lecture 8 on "Conscious Perception" constitutes necessary preparation. In lecture 9 on "Learning and Memory" the thesis is that memory is essential to anything deserving to be called knowledge: "Without memory there could not be a knowing of existence" (page 180). In lecture 10 Eccles wants to construe mind and brain as "independent entities, the brain being in World 1 and the mind in World 2 (Fig. 61)', and to urge that these are both entities which "somehow interact, as illustrated by the arrows in Figure 10-2", (page 212).

But this, as the rally-drivers say, is going a bit quick. For all our ordinary talk about minds, ordinarily understood, is just talk about certain sorts of things which some creatures of flesh and blood can and do do or suffer. To say that, for instance, she has a first-class mind just is to say that she is capable of operating at that high academic level. So if anyone wants to hypothesise some independent entities to be called minds, he has first to provide some account of how such entities are to be identified and individuated. For minds in the common everyday sense of the word are not what is required: they are not, that is to say (logical) substances things which, like chairs and tables and unlike grins and tempers, could significantly be said to exist separately and in their own right. To speak of her firstclass mind surviving her death and cremation would, in the everyday sense of 'mind', be about as sensible as speaking of the grin on the face of Alice's Cheshire Cat outlasting the cat of whose face it was a configuration. On the other hand, much of the history of philosophy since Descartes can be read as showing how difficult if not impossible it must be to think up a notion of minds as immaterial substances; which could be identified as subjects of discourse, re-identified through time, and individuated one from another.

Antony Flew is Professor of Philosophy at the University of Reading, $U K$.

\section{Precious cult of scientific knowledge}

\section{Martin Pollock}

Paradoxes of Progress. By Gunther S. Stent. Pp. 231. (Freeman: San Francisco and Reading, UK, 1978). Hardback £8; paperback $£ 3.90$.

THIS is a collection of articles on modern science, already published over the past ten years or so and now strung together, a little forcedly perhaps, under a title which can serve a multitude of themes. It is therefore, inevitably, somewhat of a ramble. The common thread is Professor Stent's own idea of what is happening to our precious cult of scientific knowledge, where it is going and what its principles mean, or should mean, for us. His opinions are worth studying, though cramped by a rather awkward style of writing and even if - or especially if - one does not agree with them. The problems he raises and the questions he asks are those which most scientists do not even like to think about, let alone try to answer.

All the essays are worth reading in their own right, although two of them - a review of Jim Watson's Double Helix and an analysis of "Prematurity and Uniqueness in Scientific Discovery" - stand rather apart from the rest, being of borderline relevance to the central issue. Three are of outstanding interest. These are: (1) "The Dilemma of Science and Morals" which discusses the many desperate problems of how our continuously expanding knowledge should be applied practically and includes a brief but fascinating comparison between the science and technology of classical China and western scientific philosophy; (2) "Limits to the Scientific Understanding of Man", being essentially a clear-cut criticism of positivism and its later manifesations in the form of simplistic acceptance of a reality that is "built on cumulative experience" alone and is now referred to as "Scientism"; and (3) "The Decadence of Scientism" ('Decline' might have been a more appropriate word), which discusses a neo-Kantian basis for understanding and a practical morality that recognises the impossibility of true objectivity or valuefree conclusions, and involves adopting what is now often referred to as a "Structuralist" and anti-beviourist approach to thinking and acting; this itself depends on analysis of "deep structures" beneath the superficialities to which alone our senses are directly responsive.

According to Stent, science, as we now know it, is on the way out. The spirit of "Faustian man" who believes in "progress", and outward striving (defined as the "will to power") is on the wane and yielding diminishing returns; it is anyway self-limiting because it seeks, and to a large extent obtains, a sense of security which quenches the thrust for more power. Faustian man, born in the ages of enlightenment of the seventeenth and eighteenth centuries and reaching maturity in the nineteenth where the solution to all problems was viewed in the context of a continuously progressive increase in knowledge and power over the outside world, is on his death bed. His spirit will be succeeded by something similar to the Polynesian-based dream of a life of ease but without grand ambitions, a rejection of the idea of "progress" and materialistic sophistications and an acceptance of the Zen principle that the recognition of subjective sensation is the only reality. The "noble savage" is not a fancy directed backwards to the distant past, but something to anticipate in the years to come. The different articles share a common theme by illustrating the problems and paradoxes which herald the end of our era. And the author, who has rightly emphasised the many analogies between science and the arts, believes that similar factors are involved in the decline of the arts which have now lost all style and discipline, become totally "freed" and will have to start again with a new impulse.

One of the first signs of the end was, according to Stent, the "beatnik" movement in Berkeley of the late 1950s and (to a later and lesser extent) the hippy creed of the 1960s. Amongst scientists themselves, the relevant factors include a growing sense of the limitations to the objectivity of our observations and conclusions and increasing estrangement between our intuitive common sense and what we have to accept as most appropriate explanations; in particular, the principle of indeterminism in physics, which is equivalent to saying that like causes do not necessarily have like effect would seem to undermine the fundamentals of scientific explanation.

Stent also refers to a phenomenon described by Mandelbrot termed "secondstage indeterminism" where probably random events, such as "noise" in an organised system, theoretically able to be eliminated by a statistical approach, nevertheless seem on analysis for limited periods, to conform to certain laws of fluctuation (for example, in coin tossing experiments). This problem is the old one of how to decide when to introduce the concept of chance and what the idea of randomness really means - a dilemma which has faced scientists for very many years. To what extent, for instance, are the structural patterns we think we see around us simply illusions, based on too superficial and prematurely completed analysis of a series of events that require an impractically long period of study for 
establishing their truly random nature?

One might go further on the basis of belief in subjective reality, and ask, even in the name of science, how many of the patterns we think exist in nature are only a reflection of pre-determined patterns in our brains. But we would still have to try and decide how our brain patterns appeared in the first instance.

Associated with the rather difficult idea of "second-stage indeterminism" is that of the "spontaneous activity of the system itself"' which Stent also pursues. This is really rather frightening. Are we to suppose that every system in nature has some inherently endowed freedom of action which transcends natural laws and is thus immune to scientific study? If so, it might still be argued by Mandelbrot (if not by Stent) that this is no more than what most people ascribe to the human organism in the form of intrinsic freewill, upon which we all base our ordinary lives (and our science) whether we believe in it or not. And so we pass on to the equally difficult concept of self and one's own consciousness, forever a stumbling block for most philosophers. Even the most positive of positivists would surely have to admit that to use the machine itself for studying the machine is begging a shattering question and must involve some crucial assumptions, such as that the "thing in itself" is "truly" (whatever that may mean) what we perceive it to be, which few of us would be prepared to accept.

The final paradoxical problem raised concerns the moral dilemma of what should be the principles guiding our actions in science. And it looks here rather as if Stent is more than just vaguely sympathetic to the Taoism of ancient China which teaches that man is part of an inscrutable nature and must retreat from personal striving in order to attain inner fulfilment. This, of course, is the direct opposite of Western science where nature is not regarded as "inscrutable", but on the contrary responds strikingly to reason and has allowed us to exploit our environment with extravagant success - at least viewed from a strictly technological angle. With Tao, "instead of Truth and Justice", he writes, "Wisdom and Harmony would [then] become the primary values". And he quotes Joseph Needham: "with their appreciation of the relativism and subtlety and immensity of the universe, [the Chinese scientists] were groping after an Einsteinian world picture without having laid the foundations for a Newtonian one". Is the implication here that, in one sense at least, the Chinese have leap-frogged Western science and could soon be way ahead on the basis of a Tao-based structure for dealing with ourselves and the world around us?

Some recent advances in brain physiology are then described, in particular the fascinating work of Hubel and Wiesel on cells of the visual cortex. This emphasises the specific selective nature of

\section{Sorry, for copyright reasons some images on this page may not be available online}

cell response to visual stimuli, indicating that patterns we "see" are made up of an integrated synthesis of the reactions of a composite of cells programmed by the combined effect of early environment and genetic predisposition to respond only to certain restricted types of input signal. This kind of selective mechanism of response to the immediate environment applies also to other types of (biochemical) cell reaction, such as enzyme induction. It is another aspect of the type of evidence that supports a "structuralist" approach to the mechanism of understanding, being closely related to Chomsky's ideas of "deep structures" in linguistics and has taken over, during the past 30 years or so, according to Stent, from the later stages of positivism expressed, for example, in "behaviourism" which is now largely discredited. And so, it is argued, we are back - or nearly so - to the original ideas of Kant in favour of "innate, a priori knowledge" (that is, not derived from experience) which could have evolved. Darwinistically, because it was the most suitable for survival at the time. And why not? If we cannot achieve absolute understanding, why not make do with the brain mechanism presumably evolved to supply the type of "explanation" most suitable for dealing with ourselves in the world as it is - or as it was!

Stent seems inclined to use a similar neoKantian method for postulating an "innate ethical deep structure", present in all human beings, which he recognises as not all that far removed from Kant's "categorical imperative", defined as an ethical principle so universally applicable that it has to be accepted as a natural law .... so obvious that it "goes without saying" - and thereby, one suspects, is different for every individual because nobody ever seems to have to formulate it in words.

One does not have to accept all or any of the implications offered in this book in order to benefit from thinking about them. The author is not very dogmatic, anyway, and only in his predictions about the end of our era in science does he attempt to make a firm case - which is, in fact, not very convincing. We may, perhaps be at a point of inflection in the development of science, but does it really amount to the end of an era? It is indeed, strange to view his arguments about the forthcoming "age of leisure" and a rejection of material efficiency, against a background of a world where nearly $50 \%$ of the population exist near or below subsistence level and the simplest types of technological improvement could, if properly applied, ease the lot of hundreds of millions of human beings. Modern science may not reveal the truth about the Universe or solve our ethical problems, but so long as people want H-bombs, space exploration, computer technology, and so on, or simply fast transport and more plentiful forms of energy and food; then our science will be needed because it alone can deliver the goods. A philosophy of pragmatism still has a lot to be said for it, but it is not much discussed here, except as a rather unimpressive spin-off of what the author dismisses as "soft-core" scientism - a less noxious type of scientism in comparison with the "hard-core" variety which maintains that science (especially biology) provides a morality (a "moral norm") of its own based on evolution and the "natural behaviour" of animals.

This is a stimulating and thoughtprovoking book which is worth reading in depth by all scientists who want to consider seriously the meaning of what they are doing and who wonder why they are sometimes pressed to discuss the philosophical implications of their work and not restrict themselves to its immediate practical results or just fiddle around with an intellectually amusing toy. Our science would be in a better position to defend itself if there were more scientists who can react to Professor Stent's arguments and at least understand what it is not; and who can realise, with A.N. Whitehead, that despite (or along with) all its practical achievements and intellectual magnificence, we are liable "to forget how strained and paradoxical is the view of nature which it [modern science] imposes on our thoughts".

Martin Pollock is Emeritus Professor of Biology in the University of Edinburgh, UK. 